Article

\title{
For Exercise, Relaxation, or Spirituality: Exploring Participation Motives and Conformity to Masculine Norms among Male and Female Yoga Participants
}

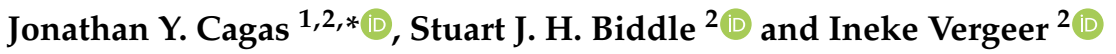 \\ 1 Department of Sports Science, College of Human Kinetics, University of the Philippines Diliman, \\ Quezon City 1101, Philippines \\ 2 Physically Active Lifestyles (PALs) Research Group, Centre for Health Research, University of Southern \\ Queensland, Springfield Central 4300, Australia; Stuart.Biddle@usq.edu.au (S.J.H.B.); \\ Ineke.Vergeer@usq.edu.au (I.V.) \\ * Correspondence: jycagas@up.edu.ph
}

check for

updates

Citation: Cagas, J.Y.; Biddle, S.J.H.; Vergeer, I. For Exercise, Relaxation, or Spirituality: Exploring Participation Motives and Conformity to Masculine Norms among Male and Female Yoga Participants. Int. J.

Environ. Res. Public Health 2022, 19, 770. https://doi.org/10.3390/ijerph 19020770

Academic Editor: Paul B. Tchounwou

Received: 22 December 2021

Accepted: 7 January 2022

Published: 11 January 2022

Publisher's Note: MDPI stays neutral with regard to jurisdictional claims in published maps and institutional affiliations.

Copyright: (C) 2022 by the authors. Licensee MDPI, Basel, Switzerland. This article is an open access article distributed under the terms and conditions of the Creative Commons Attribution (CC BY) license (https:// creativecommons.org/licenses/by/ $4.0 /)$.

\begin{abstract}
Yoga is a traditional practice from India with the potential to promote physical activity and health. Participation worldwide remains low, particularly among men. To better understand yoga participation parameters, with a special focus on what influences male participation, this study examined gender differences in participation motives and conformity to masculine norms. It also explored these factors across three participant subgroups who differed in their engagement with the physical and the more psycho-spiritual aspects of yoga. A total of 546 yoga participants (138 males, 399 females, 9 others), 18-73 years old, completed an online survey that included an adapted version of the Exercise Motivation Inventory-2 and three subscales from the Conformity to Masculine Norms Inventory-46. Results showed significant gender differences in participation motives and conformity to masculine norms. Females were more motivated by positive affect, health/fitness, nimbleness, mind-body integration, and coping/stress management, whereas males were more motivated by supplementary activity and competition/social recognition. These differences should be considered in tailoring messages to promote uptake and continued participation. Furthermore, males were more likely than females to conform to emotional control and heterosexual self-presentation masculine norms. Future research may examine how differences in masculine norm adherence influences uptake, particularly among men.
\end{abstract}

Keywords: participation motives; yoga; gender differences; holistic movement practice; masculine norms

\section{Introduction}

Yoga is a traditional practice from India acknowledged for its potential contribution to public health $[1,2]$. It involves a holistic approach to health and well-being, promoting physical activity, healthy behaviors, mental health, and psycho-spiritual development [3-6]. While yoga has become a prominent part of the modern-day physical activity landscape $[7,8]$, studies have shown that yoga participation is still relatively low and appears confined mainly to specific population subgroups [9-13], with white, well-educated females occupying a particularly prominent place. Given yoga's wide range of potential health benefits [14-18], there is ample space for participation to grow, particularly among non-dominant subpopulations such as men. Strategies for yoga promotion could benefit from knowledge of participation parameters such as people's perception of the activity and reasons for participation $[19,20]$.

In the physical activity field, yoga can be considered a holistic movement practice [6,7], indicating it involves but also goes beyond physical exercise to include mental as well as spiritual components. Yoga may thus serve various functions, and research has shown that 
yoga can indeed be perceived in different ways, for example, as a form of physical exercise or as a spiritual activity [21-23]. Such perceptions may be associated with the reasons people do or do not do yoga $[19,20]$. The study of participation motives in the physical activity field in general [24] has shown variations across gender and contexts [20,25,26]. For instance, people who engage in sports are more likely to endorse intrinsic motives such as enjoyment and mastery than those who exercise, whereas people who exercise are more likely to cite health and appearance reasons than sports participants [20,26]. It is also typically reported that men are more likely to exercise or play sports for competitive reasons than women $[27,28]$. Molanorouzi et al. [20] found that men were driven by competition and improving their skills or personal best when engaging in physical activity. In contrast, women were more motivated by physical appearance and health/fitness.

Similar to physical activity, yoga may be taken up for varying and multiple reasons, including health, fitness, self-development, mind-body integration, and spirituality [4]. Gender differences have been observed in some studies on yoga participation motives [29,30]. A study in Germany [30], for example, found that female participants were more likely to cite spirituality as a reason for participation. Furthermore, findings from a qualitative study involving non-yoga practicing men suggest that men are likely to be less interested in yoga but that they may acknowledge its potential benefits and might be open to taking it up as a supplement to an existing training program [31]. However, not all men share the same needs and interests [32,33], and this may include views on yoga. It is possible that men who consider yoga a psycho-spiritual practice would do yoga for spiritual reasons as much as women. Early research suggests there may be subgroups of participants who differ in their engagement with the psycho-spiritual aspects of yoga [23,34]. It may be useful to take such a possible subdivision into account when considering gender differences in participation motives for yoga.

Gender differences within yoga [35] deserve further study, including examining motives for participation in relation to participants' perceptions of yoga and their engagement in its psycho-spiritual underpinnings. This study aimed to address this gap, with a particular interest in generating more knowledge about men's participation motivation, in the hope that this might inform strategies for yoga promotion among this under-represented population subgroup.

Yoga's potential health benefits [14-18] make it a promising health behavior for both genders. However, as indicated above, uptake among men lags far behind that of women [9-12] and various factors may contribute to this phenomenon. Men's health behaviors are considerably influenced by standards of masculinity-existing gender role norms operating in society that expect men to behave in particular ways [36-38]. For example, society expects men to be physically and mentally tough, making them less likely to share their emotions, seek help from others, or be concerned about their health [36]. Taking care of one's health and engaging in alternative health practices like yoga are often associated with the female gender [39,40]. Men who adhere strongly to these masculine norms tend to avoid such practices as a way to maintain their male identity [39]. Strong conformity to traditional masculine standards has been attributed to poor health behaviors among men [39]. Among the many health behaviors, physical activity, particularly sports and strength training programs, tend to be more attractive to men as it reflects masculine values (e.g., physical challenge, being active, and building strength) that are important for men [32,41,42]. Promoting physical activity is, therefore, an important strategy to improve men's health $[32,43]$. Studies on health and physical activity promotion among men, however, have predominantly centered on sports to capitalize on these traditional masculine ideals [32]. Yoga is thus less commonly considered as an appropriate activity for men [31]. It has been argued that men have diverse interests and do not conform to masculine norms in similar ways $[38,44]$. Therefore, some men may not find traditional strength training and sports-centered health programs appealing [45-47]. Lack of motivation is a common barrier for physical activity among men, which could result from a lack of variety in the 
physical activity programs on offer [48]. Thus, exploring other forms of physical activity that could cater to the needs and interests of different male subgroups is important [32,33].

Because of its holistic approach to well-being [7] and preponderance of female participants [12,13], yoga can be perceived as a feminine and female-dominated activity and both those perceptions can act as a barrier for men [31]. However, there are men who practice yoga, and recent data from the United States suggest that their numbers are increasing at least somewhat [10]. In this study, we aimed to get more insight into the motivation of these men by examining participation motives and conformity to masculine norms across both genders. We also wanted to explore the existence and role of different subgroups with respect to these factors, given the research suggesting the existence of participant subgroups differing in their engagement with the psycho-spiritual aspects of yoga $[23,34]$ Identifying the reasons that best differentiate male and female participants, and those who consider yoga as a physical exercise or a spiritual practice could help develop differentiated messages that effectively target the needs of different participant subgroups. The main research question of this study was whether male and female yoga participants differ in their motives for yoga participation and conformity to certain masculine norms, in general and when considering participant type subgroups.

\section{Methods}

The study consisted of an online survey, including questions on respondents' sociodemographic background, yoga practice, motives for participation, conformity to masculine norms, perceptions of yoga as a physical, mental, and/or spiritual practice, and immersion in yoga's psycho-spiritual aspects. This paper particularly focuses on the measures of participation motives, conformity to masculine norms, and a participant type factor representing subgroup differences in engagement with yoga's psycho-spiritual side, based on the perception and immersion questions.

\subsection{Participants}

Adults, 18 years and older, who were practicing yoga at least once a week for three months prior to the onset of the COVID 19 pandemic were recruited for the study. A minimum sample size of 345 (anticipated effect size $=0.25$; power level $=0.80$; probability level $=0.05$ ) was determined a-priori using the $G^{*}$ Power program [49]. Study advertisements with a link to the online questionnaire were posted on Facebook, Instagram, Twitter, Yoga Australia's e-newsletter, and the Australian host University mailing list. Out of the 1119 individuals who accessed the link, 546 (48.8\%) completed the survey. Respondents were from the Philippines $(n=305 ; 55.9 \%)$, Australia $(n=158 ; 28.9 \%)$, and other countries ( $n=83 ; 15.2 \%)$. Participants' ages ranged from 18 to 73 years $(M=39.99, S D=11.85)$. A majority of respondents were female $(73.1 \%)$, and Asian $(62.5 \%) ; 38.5 \%$ were married, $47.6 \%$ full-time employed, and $44.5 \%$ had a bachelor's degree. Years of yoga practice varied widely from 1 to 50 years ( $M d n=5.00$ years). The most common styles were Vinyasa Yoga (32.1\%) and Ashtanga Yoga (28.3\%). The sociodemographic characteristics of the respondents are summarized in Table 1.

Table 1. Characteristics of the participants.

\begin{tabular}{lrcccc}
\hline & \multicolumn{1}{c}{ Variables } & Total & Male & Female & Others * \\
\hline $\begin{array}{l}\text { Sample size } \\
\text { Age }\end{array}$ & & 546 & $138(25.3 \%)$ & $399(73.1 \%)$ & $9(1.6 \%)$ \\
& Mean (SD) & $39.99(11.85)$ & $41.94(12.09)$ & $39.43(11.76)$ & $35.00(7.75)$ \\
Country of Residence & Range & 18 to 73 years & 21 to 69 years & 18 to 73 years & 26 to 47 years \\
& & & & & \\
& Australia & $158(28.9 \%)$ & $42(30.4 \%)$ & $114(28.6 \%)$ & $2(22.2 \%)$ \\
& Philippines & $305(55.9 \%)$ & $57(41.3 \%)$ & $242(60.7 \%)$ & $6(66.7 \%)$ \\
& Others & $83(15.2 \%)$ & $39(28.3 \%)$ & $43(10.8 \%)$ & $1(11.1 \%)$ \\
\hline
\end{tabular}


Table 1. Cont.

\begin{tabular}{|c|c|c|c|c|}
\hline Variables & Total & Male & Female & Others * \\
\hline \multicolumn{5}{|l|}{ Ethnicity } \\
\hline White & $172(31.5 \%)$ & $59(42.8 \%)$ & $113(28.3 \%)$ & $0(0.0 \%)$ \\
\hline Asian & $341(62.5 \%)$ & $66(47.8 \%)$ & $268(67.2 \%)$ & $7(77.8 \%)$ \\
\hline Mixed-race & $13(2.4 \%)$ & $5(3.6 \%)$ & $7(1.8 \%)$ & $1(11.1 \%)$ \\
\hline Others & $20(3.7 \%)$ & $8(5.8 \%)$ & $11(2.8 \%)$ & $1(11.1 \%)$ \\
\hline \multicolumn{5}{|l|}{ Employment } \\
\hline Employed full-time & $260(47.6 \%)$ & $70(50.7 \%)$ & $186(46.6 \%)$ & $4(44.4 \%)$ \\
\hline Employed part-time & $46(8.4 \%)$ & $9(6.5 \%)$ & $36(9.0 \%)$ & $1(11.1 \%)$ \\
\hline Self-employed & $139(25.5 \%)$ & $38(27.5 \%)$ & $99(24.8 \%)$ & $2(22.2 \%)$ \\
\hline Studying full-time & $35(6.4 \%)$ & $6(4.3 \%)$ & $27(6.8 \%)$ & $2(22.2 \%)$ \\
\hline Retired & $20(3.7 \%)$ & $10(7.2 \%)$ & $10(2.5 \%)$ & $0(0.0 \%)$ \\
\hline Stay at home parent/carer & $16(2.9 \%)$ & $0(0.0 \%)$ & $16(4.0 \%)$ & $0(0.0 \%)$ \\
\hline Unemployed & $15(2.7 \%)$ & $2(1.4 \%)$ & $13(3.3 \%)$ & $0(0.0 \%)$ \\
\hline Other & $15(2.7 \%)$ & $3(2.2 \%)$ & $12(3.0)$ & $0(0.0 \%)$ \\
\hline \multicolumn{5}{|l|}{ Partnership Status } \\
\hline Single & $180(33.0 \%)$ & $46(33.3 \%)$ & $130(32.6 \%)$ & $4(44.4 \%)$ \\
\hline Partnered or in a relationship & $125(22.9 \%)$ & $40(29.0 \%)$ & $83(20.8 \%)$ & $2(22.2 \%)$ \\
\hline Married/Civil partnership/De facto & $210(38.5 \%)$ & $46(33.3 \%)$ & $161(40.4 \%)$ & $3(33.3 \%)$ \\
\hline Divorced/separated & $28(5.1 \%)$ & $5(3.6 \%)$ & $23(5.8 \%)$ & $0(0.0 \%)$ \\
\hline Other (e.g., widower) & $3(0.5 \%)$ & $1(0.7 \%)$ & $2(0.5 \%)$ & $0(0.0 \%)$ \\
\hline \multicolumn{5}{|l|}{ Highest Educational Attainment } \\
\hline Less than Year 12 or equivalent & $6(1.1 \%)$ & $1(0.7 \%)$ & $5(1.3 \%)$ & $0(0.0 \%)$ \\
\hline Year 12 or High School diploma & $29(5.3 \%)$ & $6(4.33 \%)$ & $22(5.5 \%)$ & $1(11.1 \%)$ \\
\hline Vocational or Associate Diploma & $40(7.3 \%)$ & $16(11.6 \%)$ & $22(5.5 \%)$ & $2(22.2 \%)$ \\
\hline Bachelor & $243(44.5 \%)$ & $51(37.0 \%)$ & $190(47.6 \%)$ & $2(22.2 \%)$ \\
\hline Postgraduate diploma/certificate & $60(11.0 \%)$ & $11(8.0 \%)$ & $48(12.0 \%)$ & $1(11.1 \%)$ \\
\hline Master's degree & $122(22.3 \%)$ & $39(28.3 \%)$ & $80(20.1 \%)$ & $3(33.3 \%)$ \\
\hline Doctorate & $46(8.4 \%)$ & $14(10.1 \%)$ & $32(8.0 \%)$ & $0(0.0 \%)$ \\
\hline \multicolumn{5}{|l|}{ Socio-Economic Ladder } \\
\hline Mean (SD) & $6.21(1.72)$ & $6.21(1.76)$ & $6.21(1.71)$ & $6.33(1.73)$ \\
\hline Range & $1-10$ & $1-10$ & $1-10$ & 4-9 \\
\hline \multicolumn{5}{|l|}{ Yoga Teacher Status } \\
\hline Non-teachers & $397(72.7 \%)$ & $93(67.4 \%)$ & $297(74.4 \%)$ & $7(77.8 \%)$ \\
\hline Teachers & $149(27.3 \%)$ & $45(32.6 \%)$ & $25(6 . \%)$ & $2(22.2 \%)$ \\
\hline \multicolumn{5}{|l|}{ Subgroups of Yoga Participant Type } \\
\hline Exerciser & $132(24.2 \%)$ & $40(29.0 \%)$ & $90(22.6 \%)$ & $2(22.2 \%)$ \\
\hline Yogi & $204(37.4 \%)$ & $51(37.0 \%)$ & $149(37.3 \%)$ & $4(44.4 \%)$ \\
\hline Postural Yogi & $210(38.5 \%)$ & $47(34.1 \%)$ & $160(40.1 \%)$ & $3(33.3 \%)$ \\
\hline
\end{tabular}

* Not included in the group comparison due to a very small sample size.

\subsection{Measures}

\subsubsection{Motives for Yoga Participation}

We used the Exercise Motivation Inventory-2 (EMI-2) to assess a broad range of motives and adapted it for yoga participation [50]. The EMI-2 includes 51 items measuring 14 participation motives. We added 28 new items to capture six additional motives (Spirituality, Mind-Body Integration, Centering/Mindfulness, Personal Growth/Transformation, supplementary activity, and general coping) that may be salient to yoga [4]. Details of the process of developing these additional items and the preliminary factor analysis are reported elsewhere [51]. The exploratory factor analysis of the adapted EMI-2 resulted in 12 factors: Spirituality (e.g., "for spiritual growth"), Mind-Body Integration (e.g., "to have a better mind-body connection"), Coping/Stress Management (e.g., "to better cope with some challenging life events"), Health/Fitness (e.g., "to feel more healthy"), Nimbleness (e.g., "to maintain flexibility"), Challenge (e.g., "to give me goals to work towards"), Positive Affect (e.g., "because it makes me feel good"), Weight Management/Appearance (e.g., "to lose weight"), Ill-Health Avoidance (e.g., "to prevent health problems"), Affiliation (e.g., "to spend time with friends"), Competition/Social Recognition (e.g., "to show my worth to 
others"), and Supplementary Activity (e.g., "because it will help me in my sport or other physical activity"). Internal reliability coefficients were high, ranging from 0.85 to 0.97 . Participants indicated whether or not each statement was true for them using a 6-point Likert-type scale ranging from 0 (Not at all true for me) to 5 (Very true for me).

\subsubsection{Conformity to Masculine Norms}

The Conformity to Masculine Norms Inventory-46 [52,53] assesses the extent to which an individual adheres to nine traditional masculine norms. Owen [54] suggested selecting only the masculine norms that may be salient to the topic. In this study, we assessed only three norms: Emotional Control (e.g., "I tend to keep my feelings to myself"), Heterosexual Self-Presentation (e.g., "I would feel uncomfortable if someone thought I was gay"), and Self-Reliance (e.g., "I never ask for help"). Internal reliability coefficients of these three subscales ranged from 0.85 to 0.87 . Because of the feminine and female-dominated nature of yoga [31], we believed these norms would be the most relevant. Participants indicated the extent to which they agreed or disagreed with each statement using a 4-point scale ranging from 0 (strongly disagree) to 3 (strongly agree). Means for each subscale were computed, with higher scores reflecting greater conformity.

\subsubsection{Yoga Participant Subgroups}

Participants were categorized into Exercisers, Yogis, and Postural Yogis. This categorization was based on a two-step cluster analysis on three clustering variables: perceptions of yoga as a physical practice, perceptions of yoga as a psycho-spiritual practice, and yoga immersion (i.e., level of engagement in the psycho-spiritual aspects of yoga) [55]. Details of the cluster analysis are reported elsewhere [51]. Exercisers were yoga participants who perceived yoga mainly as a physical practice and were the least involved in yoga's psycho-spiritual dimensions. Yogis were participants who regarded yoga more as a psycho-spiritual discipline and less as a physical practice; they were highly immersed in yoga's psycho-spiritual teachings. Postural Yogis were those who viewed yoga both as a physical practice and a psycho-spiritual discipline and were also highly involved in its psycho-spiritual aspects.

\subsection{Data Analyses}

Preliminary data screening was performed prior to the main analyses [56]. To examine differences in participation motives and conformity to masculine norms across gender and participant type, two multivariate analyses of covariance (MANCOVA) were conducted. In the first analysis, participation motives were entered as dependent variables with gender and participant type as independent variables, and age, years of practice, and teacher status as covariates. This analysis was repeated without the covariates. When appropriate, a discriminant function analysis (DFA) was conducted as a follow-up on the main effects. Multiple group comparisons with Bonferroni corrections were used for the subgroup analyses. The same procedure was followed in the second analysis but with the three conformity to masculine norms subscales as dependent variables. All statistical analyses were executed using IBM SPSS Statistics for Macintosh, version 27.0 (IBM Corp., Armonk, NY, USA) [57].

\section{Results}

Seven multivariate outliers (Mahalanobis' distance values $>32.91, p=0.001$ ) were identified and removed from the analyses. Overall, the top motives for yoga participation were Positive Affect $(M=4.19, S D=0.96)$, Health/Fitness $(M=4.14, S D=0.95)$ and Nimbleness $(M=4.14, S D=1.06)$. Competition/Social Recognition $(M=0.98, S D=1.07)$ was the least endorsed motive. 


\subsection{Gender Differences in Participation Motives}

Results from the MANCOVA $(n=530)$ indicated significant main effects for gender, Pillai's Trace $=0.137, F(12,510)=6.733, p<0.001, \eta p^{2}=0.137$; and gender by participant type interaction, Pillai's Trace $=0.093, F(24,1022)=2.081, p<0.01, \eta p^{2}=0.047$. The three covariates were also significant: Age, Pillai's Trace $=0.118, F(12,510)=5.66, p<0.001$, $\eta p^{2}=0.118$; Years of Practice, Pillai's Trace $=0.07, F(12,510)=3.178, p<0.001, \eta p^{2}=0.07$; and Teacher Status, Pillai's Trace $=0.046, F(12,510)=2.055, p<0.05, \eta p^{2}=0.046$ (Supplementary Tables S2-S8). Age correlated positively with Nimbleness and negatively with Positive Affect, Mind-Body Integration, Coping/Stress Management, Spirituality, Challenge, Weight Management/Appearance, Supplementary Activity, and Competition/Social Recognition. When gender was considered, the relationships between Age and Positive Affect, Nimbleness, Challenge, and Competition/Social Recognition were significant only for women, and Spirituality and Weight Management/Appearance were significant only for men. Years of Practice correlated positively with Spirituality, and negatively with Health/Fitness, Challenge, Weight Management/Appearance, Supplementary Activity, and Competition/Social Recognition. When gender was considered, the relationships between Years of Practice and motives such as Spirituality, Weight Management/Appearance, and Competition/Social Recognition were significant only for women, whereas Supplementary Activity was significant only for men. Teachers reported higher Positive Affect, Mind-Body Integration, Coping/Stress Management, Ill-Health Avoidance, and Spirituality than Non-Teachers, whereas Non-Teachers reported higher Nimbleness than Teachers. These differences were also observed when the data was split by gender, except for three motives. Male teachers rated Positive Affect, Ill-health Avoidance, and Affiliation higher than male non-teachers. No significant differences were observed in these motives between female teachers and female non-teachers. The same significant result was obtained when the analysis was repeated without the covariates (i.e., MANOVA), Pillai's Trace $=0.0137, F$ $(12,513)=6.782, p<0.001, \eta p^{2}=0.137$.

Pairwise comparisons revealed significant gender differences in Positive Affect $(p<0.001)$, Health/Fitness $(p<0.001)$, Nimbleness $(p<0.05)$, Mind-Body Integration $(p<0.001)$, Coping/Stress Management $(p<0.001)$, Supplementary Activity $(p<0.01)$, and Competition/Social Recognition $(p<0.05)$. Inspecting the means (Table 2$)$ indicated that female participants rated Positive Affect, Health/Fitness, Nimbleness, Mind-Body Integration, and Coping/Stress Management higher than male participants, whereas male participants rated Supplementary Activity and Competition/Social Recognition higher than their female counterparts.

These differences were further supported by a discriminant function analysis (DFA) with prior probabilities computed from the actual group sizes, which revealed a significant canonical function, Wilks' $\lambda=0.87, \chi^{2}(12)=74.66, p<0.001$. This result indicates that male and female yoga participants could be discriminated effectively by the motives, with $75.6 \%$ of cases correctly classified into gender. Based on a minimum discriminant function loading of 0.30 [56], Coping/Stress Management (-0.635), Positive Affect (-0.580), Mind-Body Integration (-0.500), and Health/Fitness $(-0.487)$ contributed most to gender differences [58], with Supplementary Activity (0.272), Nimbleness (-0.251), and Competition/Social Recognition (0.241) providing a small contribution. 
Table 2. Descriptive statistics of participation motives by gender and participant types.

\begin{tabular}{|c|c|c|c|c|c|c|c|c|}
\hline \multirow{3}{*}{$n(\%)$} & \multicolumn{2}{|c|}{ Overall } & \multicolumn{2}{|c|}{ Exercisers } & \multicolumn{2}{|c|}{ Yogis } & \multicolumn{2}{|c|}{ Postural Yogis } \\
\hline & \multicolumn{2}{|c|}{$530(100 \%)$} & \multicolumn{2}{|c|}{$127(24 \%)$} & \multicolumn{2}{|c|}{$198(37.3 \%)$} & \multicolumn{2}{|c|}{$205(38.7 \%)$} \\
\hline & Female & Male & Female & Male & Female & Male & Female & Male \\
\hline$n(\%)$ & $394(74.3 \%)$ & $136(25.7 \%)$ & $8916.8 \%)$ & $38(7.2 \%)$ & $147(27.7 \%)$ & $51(9.6 \%)$ & $158(29.8 \%)$ & $47(8.9 \%)$ \\
\hline Motives & M (sd) & $M(s d)$ & M (sd) & M (sd) & M (sd) & M (sd) & M (sd) & M (sd) \\
\hline Positive Affect & $4.33^{* * *}(0.77)$ & $3.86(1.18)$ & $3.96^{* * *}(0.89)$ & $3.03(1.38)$ & $4.26 *(0.76)$ & $3.96(1.01)$ & $4.61(0.58)$ & $4.43(0.7)$ \\
\hline Health/Fitness & $4.27^{* * *}(0.84)$ & $3.88(1.03)$ & $4.06(0.93)$ & $3.75(0.81)$ & $4.07^{* * *}(0.91)$ & $3.4(1.18)$ & $4.57(0.61)$ & $4.5(0.62)$ \\
\hline Nimbleness & $4.23 *(0.99)$ & $4(1.11)$ & $4.28(0.86)$ & $4.26(0.85)$ & $3.86^{* *}(0.19)$ & $3.35(1.29)$ & $4.54(0.7)$ & $4.49(0.67)$ \\
\hline Mind-Body Integration & $4.04^{* * *}(1.08)$ & $3.53(1.45)$ & $2.82 * * *(1.23)$ & $1.89(1.37)$ & $4.33(1.74)$ & $4.16(1.86)$ & $4.47 *(0.68)$ & $4.17(0.87)$ \\
\hline Coping/Stress Management & $3.95^{* * *}(1.07)$ & $3.29(1.46)$ & $3.09^{* * *}(1.14)$ & $2.05(1.52)$ & $4.08 * *(1.94)$ & $3.60(1.09)$ & $4.31 *(0.86)$ & $3.95(1.11)$ \\
\hline Ill-Health Avoidance & $3.07(1.31)$ & $2.87(1.38)$ & $2.64(1.25)$ & $2.44(1.31)$ & $2.93(1.31)$ & $2.68(1.29)$ & $3.44(1.26)$ & $3.43(1.36)$ \\
\hline Spirituality & $2.83(1.66)$ & $2.71(1.84)$ & $0.84(0.85)$ & $0.64(1.03)$ & $3.69(1.24)$ & $3.65(1.22)$ & $3.15(1.43)$ & $3.37(1.59)$ \\
\hline Challenge & $2.82(1.27)$ & $2.69(1.49)$ & $2.43 *(1.16)$ & $1.92(1.36)$ & $2.62(1.28)$ & $2.4(1.45)$ & $3.24(1.22)$ & $3.61(1.11)$ \\
\hline Weight Management/Appearance & $2.41(1.46)$ & $2.4(1.5)$ & $2.32(1.45)$ & $2.06(1.51)$ & $2.14(1.43)$ & $1.9(1.29)$ & $2.73(1.45)$ & $3.22 *(1.39)$ \\
\hline Supplementary Activity & $2.31(1.78)$ & $2.74 *(1.72)$ & $2.47(1.71)$ & $3.04 *(1.51)$ & $2.18(1.74)$ & $2.1(1.6)$ & $2.33(1.85)$ & $3.18^{* *}(1.84)$ \\
\hline Affiliation & $1.76(1.40)$ & $1.83(1.56)$ & $1.60(1.39)$ & $1.13(1.35)$ & $1.67(1.39)$ & $1.75(1.48)$ & $1.93(1.39)$ & $2.49 *(1.57)$ \\
\hline Competition/Social Recognition & $0.93(1.06)$ & $1.16 *(1.27)$ & $0.83(0.91)$ & $0.86(1.06)$ & $0.90(1.01)$ & $0.89(1.06)$ & $1.01(0.98)$ & $1.68^{* * *}(1.48)$ \\
\hline
\end{tabular}

${ }^{* * *}$ Significant difference between the genders: ${ }^{* * *} p<0.001 .{ }^{* *} p<0.01 ;{ }^{*} p<0.05$. 


\subsection{Gender, Participant Subgroups, and Participation Motives}

As indicated in Table 1, about a quarter (24.2\%) of the respondents were classified as Exercisers. The rest was evenly divided among Yogis (37.4\%) and Postural Yogis (38.5\%). Within gender, the percentage Yogis was similar in both gender groups at about 37\%. Although the percentage Exercisers was higher among males (29.0\%) than among females $(22.6 \%)$ and the percentage Postural Yogis was lower among males $(34.1 \%)$ than among females $(40.1 \%)$, the test of proportions showed no significant association between gender and participant subgroups, $\chi^{2}(2)=2.01, p=0.37$.

\subsubsection{Gender Differences in Participation Motives within Participant Subgroups}

Multiple group comparisons with Bonferroni corrections revealed significant gender differences in participation motives within participant groups (Figure 1 and Table 2). Within the Exercisers subgroup, gender differences were found in Positive Affect, Mind-Body Integration, Coping/Stress Management, and Challenge, with male Exercisers rating these motives lower than female Exercisers. Within the Yogis subgroup, gender differences were observed in Positive Affect, Health/Fitness, Nimbleness, and Coping/Stress Management, with male Yogis rating these motives lower than female Yogis. Within Postural Yogis, gender differences were identified in Mind-Body Integration, Coping/Stress Management, Weight Management/Appearance, Supplementary Activity, Affiliation, and Competition/Social Recognition. Male Postural Yogis rated Mind-Body Integration and Coping/Stress Management lower, and Weight Management/Appearance, Supplementary Activity, Affiliation, and Competition/Social Recognition higher than female Postural Yogis.

\subsubsection{Participation Motives within Participant Subgroups per Gender}

Significant differences were also found within gender subgroups. Among males (Figure 2a and Supplementary Table S10), the three participant subgroups differed significantly in all motives. Postural Yogis and Exercisers differed significantly in most motives but two. Postural Yogis scored higher than Exercisers on all motives except for Nimbleness and Supplementary Activity, where both subgroups scored similarly. Postural Yogis and Yogis also differed significantly on almost all motives, with Postural Yogis scoring higher on most motives except for Positive Affect, Mind-Body Integration, and Coping/Stress Management, where the scores were similar, and Spirituality, where the Yogis scored higher. Yogis and Exercisers differed on half of the motives, with Yogis scoring higher than Exercisers on Positive Affect, Mind-Body Integration, Coping/Stress Management, and Spirituality, and lower on Nimbleness and Supplementary Activity.

Among females (Figure $2 \mathrm{~b}$ and Supplementary Table S11), the three participant subgroups differed significantly in most motives except in Supplementary Activity, Affiliation, and Competition/Social Recognition, where the scores were similar. Postural Yogis scored higher than Exercisers in all other motives except Nimbleness and Weight Management/Appearance, where the scores were not statistically different. Postural Yogis scored higher than Yogis in all other motives except in Mind-Body Integration and Coping/Stress Management, where the scores were similar, and in Spirituality, where yogis scored higher than Postural Yogis. Yogis scored higher than Exercisers in five motives (Positive Affect, Mind-Body Integration, Coping/Stress Management, and Spirituality) and lower in one motive (Nimbleness). Both Yogis and Exercisers scored similarly in Health/Fitness, Ill-Health Avoidance, and Challenge motives. 


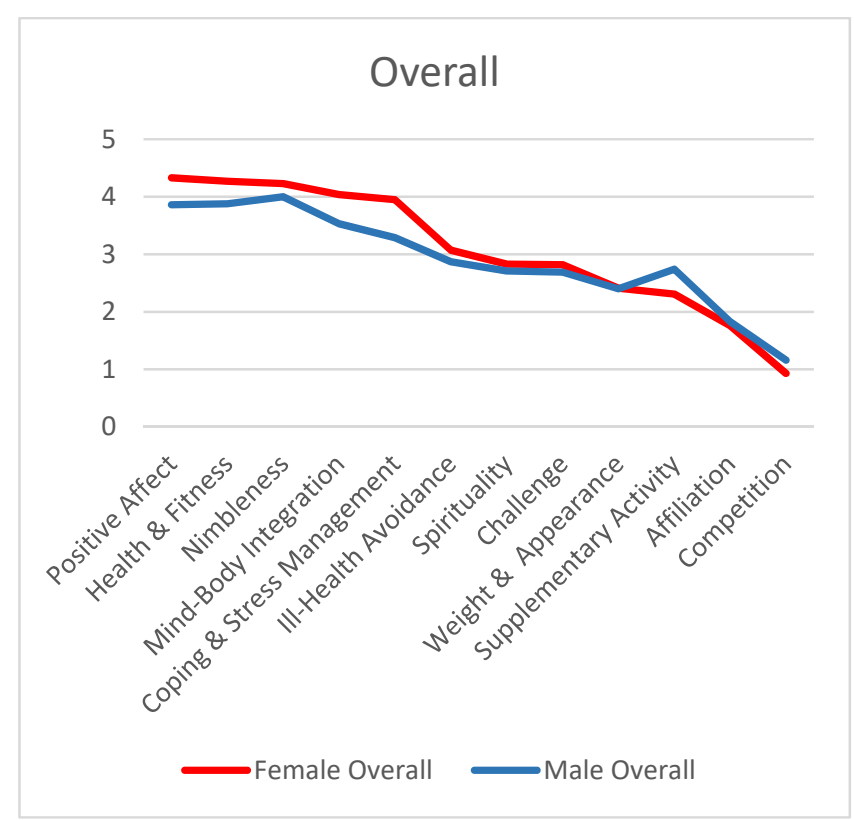

(a)

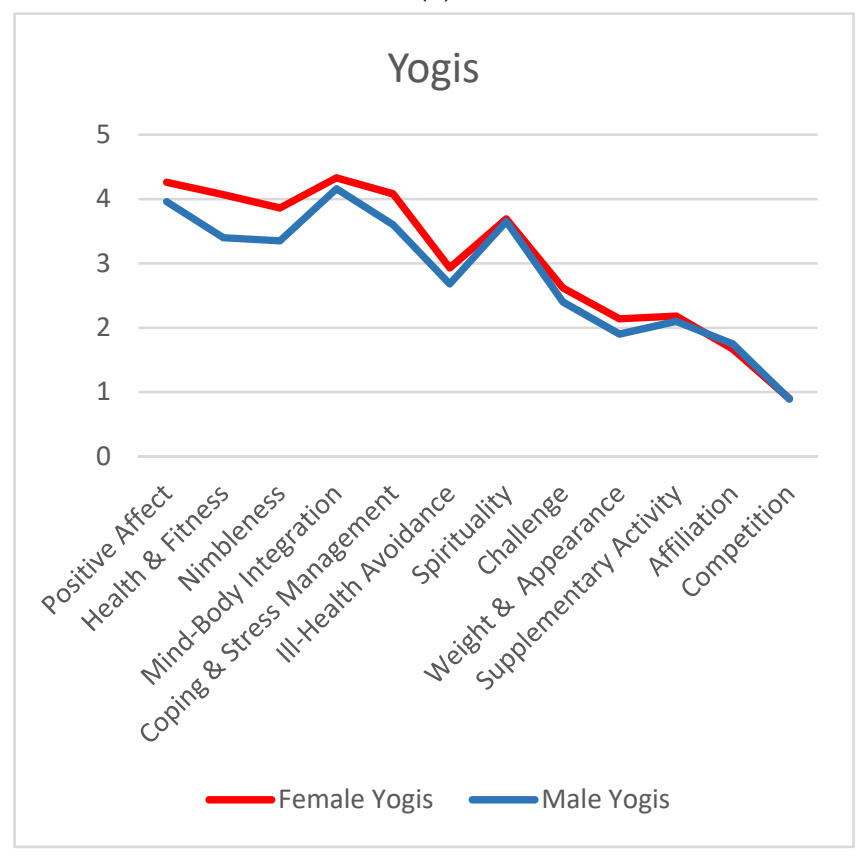

(c)

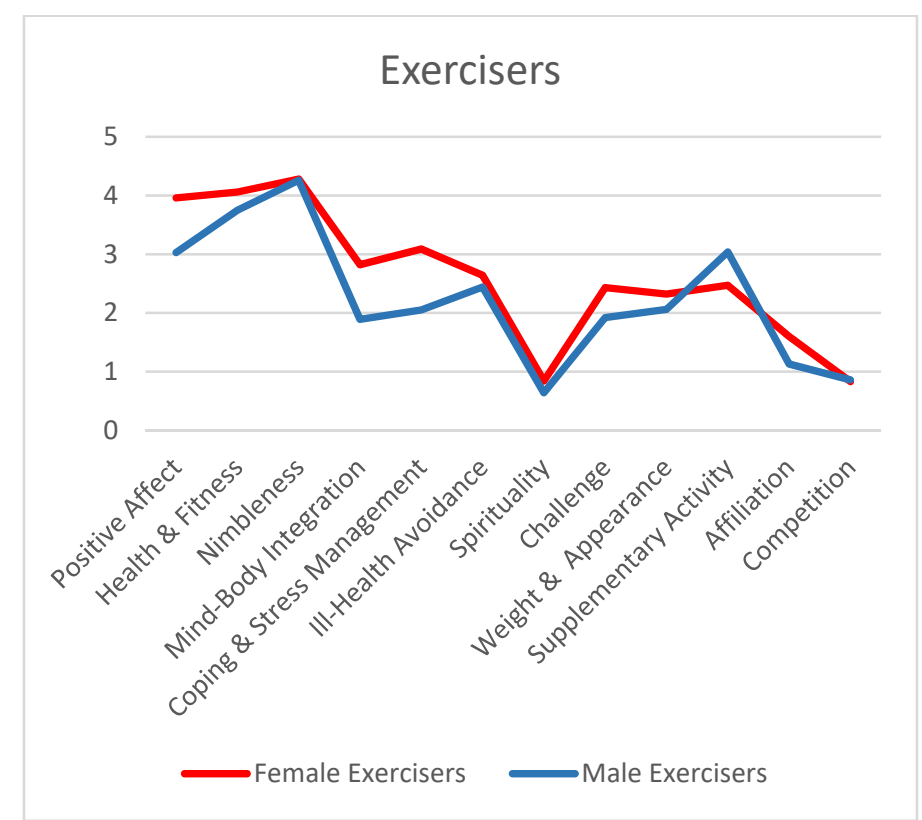

(b)

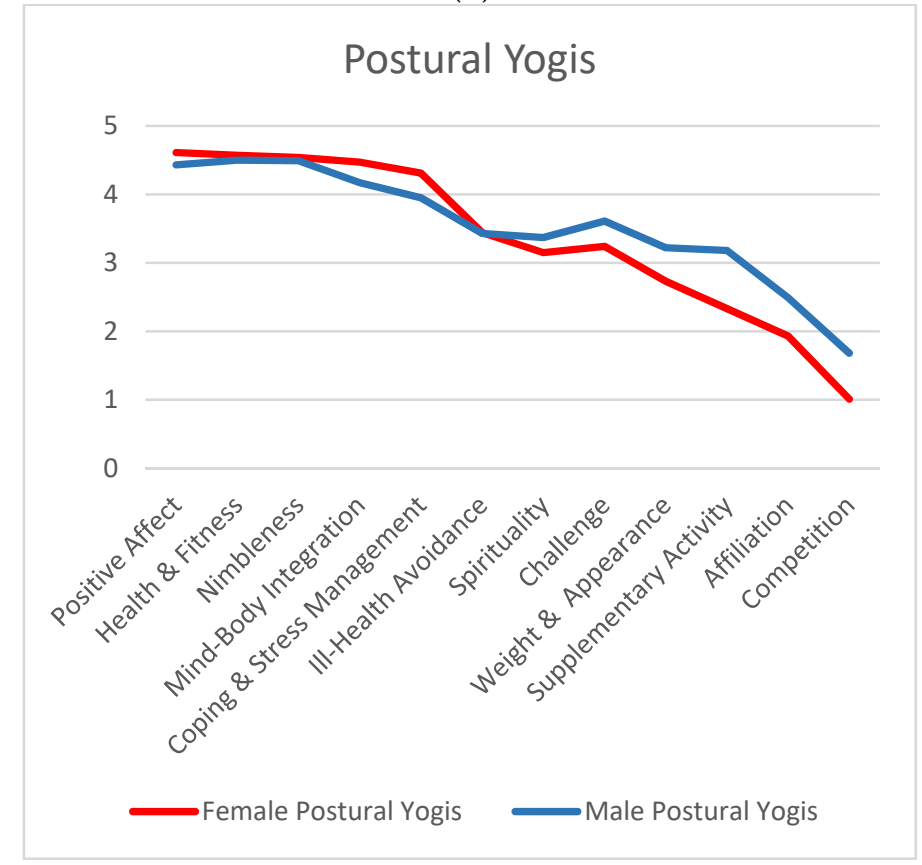

(d)

Figure 1. Mean scores on participation motives per gender, for (a) all participants, (b) Exercisers subgroup, (c) Yogis subgroup, and (d) Postural Yogis subgroup. 


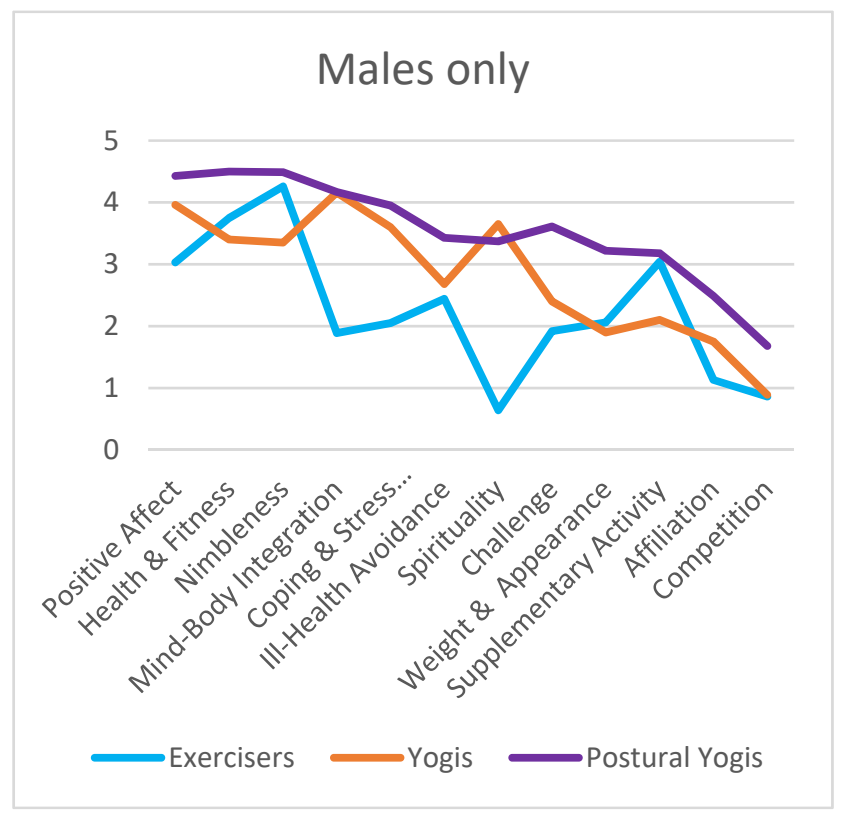

(a)

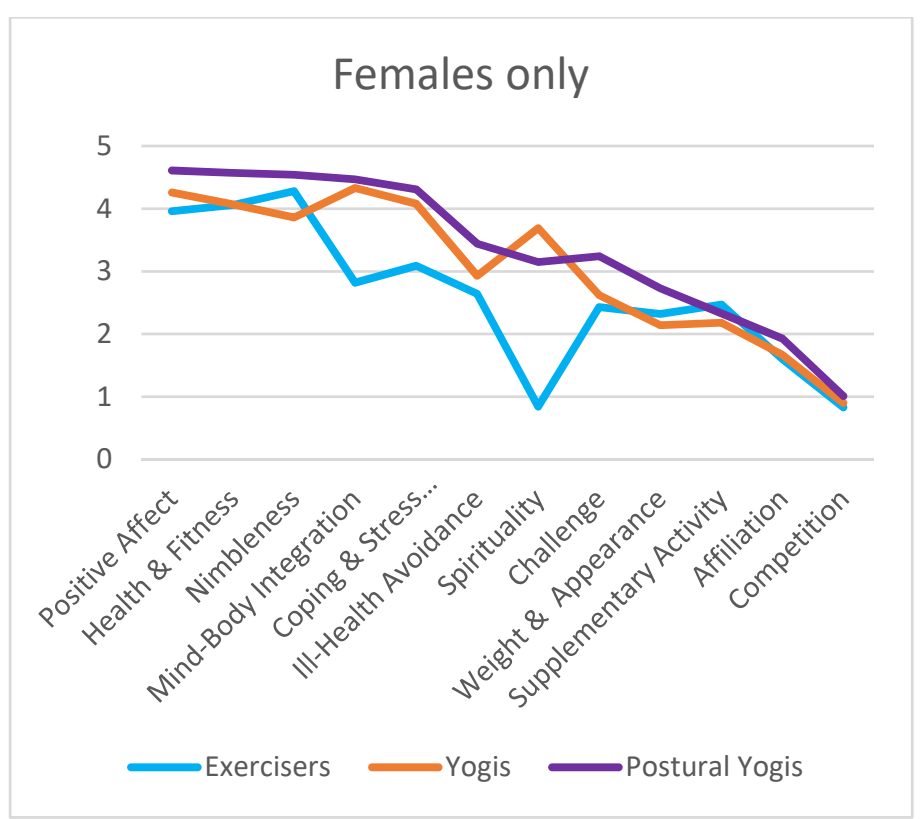

(b)

Figure 2. Mean scores on participation motives per participant subgroup, for (a) males only and (b) females only.

\subsection{Gender, Participant Subgroups, and Conformity to Masculine Norms}

\subsubsection{Gender Differences in Conformity to Masculine Norms}

Results from the second MANCOVA indicated significant main effects for gender, Pillai's Trace $=0.021, F(3,519)=3.794, p<0.01, \eta p^{2}=0.021$. The gender by participant type interaction, however, was not significant. The three covariates (age, teacher status, and years of practice) were also not significant. The same significant result was obtained when the analysis was repeated without the covariates, Pillai's Trace $=0.024, F(3,522)=$ 4.227, $p<0.01, \eta p^{2}=0.024$.

Pairwise comparisons showed male yoga participants reported higher Emotional Control, $p=0.008$, and Heterosexual Self-Presentation, $p=0.027$ compared to female yoga participants (Table 3). However, no significant gender difference was found in Self-Reliance, $p=0.604$.

Table 3. Descriptive statistics of Conformity to Masculine Norms subscales by gender and participant types.

\begin{tabular}{ccccccccc}
\hline & \multicolumn{2}{c}{ Overall } & \multicolumn{2}{c}{ Exercisers } & \multicolumn{2}{c}{ Yogis } & \multicolumn{2}{c}{ Postural Yogis } \\
\hline & Male & Female & Male & Female & Male & Female & Male & Female \\
\cline { 2 - 9 } Masculine Norm & $\mathbf{M ~ ( s d )}$ & $\mathbf{M}(\mathbf{s d})$ & $\mathbf{M}(\mathbf{s d})$ & $\mathbf{M}(\mathbf{s d})$ & $\mathbf{M}(\mathbf{s d})$ & $\mathbf{M}(\mathbf{s d})$ & $\mathbf{M}(\mathbf{s d})$ & $\mathbf{M}(\mathbf{s d})$ \\
\hline Emotional Control & $2.36^{* *}(0.56)$ & $2.19(0.58)$ & $2.39(0.70)$ & $2.32(0.63)$ & $2.40 *(0.49)$ & $2.18(0.54)$ & $2.30(0.50)$ & $2.13(0.58)$ \\
$\quad$ Self-Reliance & $2.17(0.53)$ & $2.13(0.60)$ & $2.14(0.46)$ & $2.19(0.59)$ & $2.22(0.55)$ & $2.15(0.58)$ & $2.14(0.56)$ & $2.07(0.61)$ \\
$\begin{array}{c}\text { Heterosexual } \\
\text { Self-Presentation }\end{array}$ & $1.8^{*}(0.61)$ & $1.66(0.57)$ & $1.78(0.68)$ & $1.71(0.68)$ & $1.79(0.53)$ & $1.69(0.54)$ & $1.83 *(0.65)$ & $1.61(0.52)$ \\
\hline
\end{tabular}

*** Significant difference between the genders: ${ }^{* * *} p<0.001 .{ }^{* *} p<0.01 ;{ }^{*} p<0.05$.

3.3.2. Gender Differences in Conformity to Masculine Norms within Participant Subgroups

When yoga participant subgroups were examined separately, male Yogis reported higher Emotional Control than female Yogis, $t(196)=2.532, p=0.012$, and male Postural Yogis reported higher Heterosexual Self-Presentation than female Postural Yogis, $t(203)=2.381, p=0.018$. When examining gender separately, no significant differences were found across the participants subgroups for either gender. 


\section{Discussion}

The present study examined whether participation motives and conformity to certain masculine norms vary across gender and type of yoga participants. Results indicated that, overall, participation motivation in yoga and conformity to masculine norms differed significantly between the genders. Males were more motivated than females to do yoga as a supplement for their other sports or physical activities and to display competitiveness. In contrast, females were more motivated than males by mind-body integration, health/fitness, positive affect, nimbleness, and coping/stress management. There were, however, variations in these differences when comparing participant subgroups. Coping/stress management most consistently distinguished the genders, followed by positive affect, mind-body integration, and supplementary activity, which distinguished the genders in two of the three subgroups. With respect to masculine norms, male yoga participants were more likely to demonstrate emotional control and present themselves as heterosexual compared with female yoga participants. Overall, the results suggest that it may be important to differentiate yoga messages for increased participation. Particularly when encouraging men to participate, different aspects may need to be emphasized. The results also highlight the potential role of masculinity in men's participation experience in yoga.

\subsection{Differences in Participation Motives}

Research has consistently shown that differentiation in motives underlie men and women's participation in physical activity, including yoga $[20,30,59]$. This differentiation in motives was also reflected in our findings. More specifically, our results indicate that compared to women, men are more likely to do yoga as a supplementary activity and for competitive and social recognition reasons, and less likely to cite motives related to mind-body integration, health/fitness, positive affect, nimbleness, and coping/stress management. Doing yoga to supplement their primary sport or physical activity, including injury recovery, was a salient motive for men, which is in line with previous studies $[4,31]$. It is, however, noteworthy that there were no gender differences in ill-health avoidance and weight management/appearance motives. Previous studies have typically found these types of motives to be higher among females [20,60]. This may imply that the nature of yoga attracts not only women but also men who seek such physical benefits from yoga. For male Postural Yogis, weight and appearance motives were even higher than for female Postural Yogis, suggesting that this was a particular subgroup of men valuing physical health and appearance effects.

For both genders, but particularly so for males, Postural Yogis had the highest scores on all motives (with the exception of spirituality, where Yogis scored higher, but this was still a fairly important motive for Postural Yogis), suggesting that this subgroup was most strongly and most widely motivated. The group of Postural Yogis was proportionally smaller among males than among females, suggesting that this combination of wide interests may be less common among male yoga participants. To what extent this reflects the presence of this subgroup in the wider male population remains to be investigated, along with possible other characteristics of this subgroup of men. However, it suggests there is a subgroup of men who feel attracted by both physical and non-physical components of yoga.

Although men's motivation to practice physical activity seems inconsistent with the non-competitive and non-performance principles of yoga, yoga still falls within the domain of physical activity, providing men with opportunities to demonstrate traditional masculine ideals, such as comparing their abilities with others and displaying their physical strength $[41,61]$. Highlighting the potential of yoga to supplement sports and exercise may therefore appeal better to men. However, not all men are necessarily attracted to these conventional activities $[45,46]$. For example, two studies involving male yoga participants reported that one reason why men practiced yoga was that they found yoga more meaningful compared to sport and other conventional physical activities [62,63]. It is possible that the men in these studies particularly represented Yogis and Postural Yogis, who value not only health benefits but also opportunities for self-inquiry and personal transformation. 
Future research, however, needs to investigate this further as we did not ask participants whether yoga was their primary form of physical activity. Future research may also investigate whether different types of male yoga practitioners come with different needs and/or derive different benefits from yoga. Competition was the lowest motive for all female subgroups and one of the lowest motives for all male subgroups (the lowest for Yogis and Postural Yogis, and the second lowest for Exercisers), reflecting the non-competitive nature of yoga. This confirms that yoga may be a good alternative form of physical activity for men who are not attracted to traditional competitive forms of physical activity. At the same time, yoga could appeal to men who do have competitive interests in sports or exercise as a form of supplementary activity.

In contrast to previous studies suggesting that men are less likely than women to cite spirituality as a motive for yoga participation [30], our results showed no significant gender difference in this motive. Differences in the importance of spirituality were found between yoga participant subgroups, rather than between the genders. Spirituality was an important motive for both male and female Yogis and Postural Yogis, and the least important motive for Exercisers regardless of gender. Yoga, by origin, is a psycho-spiritual discipline and thus includes spiritual practices such as chanting and rituals [64]. While these practices could act as barriers to those who hold strong religious beliefs, they could also facilitate participation in those who are already interested in spirituality and other traditions $[4,65]$.

\subsection{Masculinity, Femininity, and Masculine Norms}

The holistic spirituality and well-being associated with yoga generally fit with traditional feminine ideals $[40,66]$, which is a reason why yoga is often stereotyped as a feminine activity. This stereotyping could act as a barrier to participation to some men, especially if they hold strong traditional masculine beliefs [67].

Society generally expects men and women, to behave in particular ways and engage in gender-appropriate activities [36]. As a result, men and women avoid engaging in activities that contradict these gender expectations, as these could lead to gender role conflicts and adverse psychological outcomes (e.g., self-devaluation) [68]. The socio-cultural contexts influencing men's decision to pursue or avoid certain types of physical activities, therefore, cannot be ignored. However, men do not belong to a single homogenous group and may express their masculinities in various ways [69-71]. Studies on alternative health practices suggest men learn to navigate this potential conflict by using instrumental reasons (e.g., to recover from injuries) and downplay the 'feminine' aspects of such practices (e.g., discussing health and emotions) to justify their involvement in these socially perceived feminine activities [72,73].

As anticipated and consistent with the broader literature on masculine norms [74], the results indicated that male yoga participants were more likely to adhere to masculine norms compared to female yoga participants. More specifically, male yoga participants were more concerned about expressing emotions and about being thought of as gay than female yoga participants, although the genders did not differ on self-reliance. The feminine and female-dominated nature of yoga may thus be challenging even to males who have found their way into yoga, but it is possible that men who practice yoga are able to alter the feminine-coded practice of yoga by using logic and rationality to explain their participation, similar to other men who engage in other feminine-stereotyped activities such as vegetarianism/veganism [75], complementary and alternative medicine [73], or health [76].

It is worth noting that when gender differences were examined within participant subgroups, only male Yogis reported higher conformity to emotional control, and only male Postural Yogis reported higher conformity to heterosexual self-presentation than their female counterparts. The experience and control of emotions is an interesting phenomenon in the context of yoga. Studies have shown that that conformity to the masculine norm of emotional control may act as a protective buffer helping men to avoid anger and stress [77], 
and other maladaptive behaviors, such as binge drinking [78]. The practice of yoga involves stress management techniques, such as relaxation, breathing, and meditation, promoting emotional self-regulation [79]. Therefore, it is possible that with long-term practice, the type of control that men use may shift from suppressing to recognizing and internally regulating their emotions. This would serve the masculine norm of not expressing emotions in a healthier way, and this may be what underlies the higher scores of the male Yogis. In contrast, female Yogis may learn to express a broader range of emotions and cope better when talking to others. Males and females have been shown to cope with stress differently, with men more likely to use emotional inhibition than women while women are more likely to use emotional coping than men [80]. An interesting direction for future research would be to explore what happens to emotion regulation with prolonged yoga practice, and to what extent this affects typical gender differences in emotional control.

While conformity to the masculine norms of emotional control and heterosexual selfpresentation was stronger for male than for female participants, there were no differences in adherence to masculine norms between the participant subgroups, neither among females nor among males. The fact that conformity to masculine norms did not differ among the male subgroups suggests that, generally, the pressure to conform to masculine norms is present among all yoga-practicing men. An interesting question is to what extent the conformity to masculine norms of male yoga participants differs from conformity to masculine norms by other groups of men. A brief perusal of the literature shows that the mean scores of the three conformity to masculine norms dimensions in the present study were comparable to those reported in a study involving American men [53], but were higher than those reported in studies involving predominantly Caucasian men [81-83] and Asian Americans [82]. Future studies will need to directly compare conformity to masculine norms between yoga-participating and non-yoga participating men, and may also investigate how yoga-participating men construe their masculinity within a (currently) female-dominated context, and how they overcame any barriers associated with the feminine and femaledominated nature of yoga.

Another noticeable gender difference in this study was the fact that a third of the male respondents were yoga teachers compared to only $6 \%$ of the female respondents. Whether this is an artefact of a stronger tendency of male yoga teachers (compared to male participants) to respond to the survey or an indication that men who do find their way to yoga are more likely than women to become teachers is an intriguing question that deserves further study.

\subsection{Implications for Yoga Promotion among Men}

The results suggest that men might be more receptive to yoga if it is promoted as a supplementary activity or rehabilitation modality. Studies in the United States have shown that yoga is one of the most commonly used complementary approaches to improve athletic performance [84], and it is also one of the most commonly recommended complementary health approaches by general practitioners [85]. Male participants have remained a minority in yoga in most Western societies $[12,35,86,87]$. Therefore, encouraging more general practitioners to promote yoga to their male patients as a supplementary activity may be a useful strategy to help men be more receptive to yoga. There is undoubtedly room for increased participation among men as yoga also has the potential to promote healthier lifestyle behaviors [88,89]. Highlighting how yoga could help men improve in their primary physical activity or enhance their athletic performance might encourage increased uptake. For example, yoga classes that focus on mobility, core stability, and flexibility may be more enticing for men. Although it is generally acknowledged that increasing awareness does not necessarily result in a change in behavior [90], one study reported that non-yoga practicing men found brief information sessions helpful in making them understand the principles behind yoga and what other benefits it could offer [31]. Providing short information sessions or optional men-only introductory classes may be useful in increasing yoga uptake among men. 
In both male and female participants, spirituality and mind-body integration were motives that distinguished Yogis from Postural Yogis and Exercisers, and Postural Yogis from Exercisers. As demonstrated in a previous qualitative study [23,34], some yoga participants do yoga for spiritual reasons and have deeper engagement in its psychospiritual aspects. The present results indicate that, similar to women, some men are motivated to do yoga primarily for health and fitness reasons while others are driven by spirituality, self-exploration, and personal growth. Promoting yoga to men may therefore depend on what men seek. On one hand, the potential of yoga as a supplementary training program for sports can be emphasized when promoting yoga to men who are seeking alternative forms of physical exercise or physical therapy. Highlighting the spiritual and mind-body sides of yoga, on the other hand, may also be helpful to capture men who are more interested in benefits beyond physical exercise and performance. Acknowledging differentiation among men is therefore essential to promote increased yoga uptake.

\subsection{Strengths and Limitations}

While this study may be the first to demonstrate gender differences in participation motives and conformity to masculine norms in various yoga participant subgroups, some limitations need to be noted. First, the cross-sectional design does not allow for an analysis of how participation motives may change over time or how conformity to masculine norms influenced participation adherence. Future investigations should employ longitudinal designs to investigate mechanisms that drive changes in motivation and adherence to traditional masculinity norms and how these changes influence yoga participation uptake and maintenance. Second, the use of self-report data increased the likelihood of social desirability bias. Future studies could include measures to minimize this or use mixed methods designs to provide more diverse and robust data. Third, self-selection bias is possible due to the online survey design, recruitment, and data collection method. We exerted effort to recruit across a wide range of participants (e.g., demographics and practice styles). Nevertheless, we acknowledge that our study participants were highly educated, mostly Vinyasa and Ashtanga yoga practitioners, and more than half coming from the Philippines. The physical activity landscape in the Philippines is strongly influenced by the United States [91,92]. While we recognize the potential influence of socio-cultural factors, the way people understand and practice yoga in the Philippines is likely to be comparable to those from other Western societies. Future investigations would benefit by replicating the present study in different populations to extend its generalizability. Fourth, we acknowledge the unequal distribution of male and female participants. While we tried to recruit as many male yoga participants as possible, the challenge was that they were simply outnumbered by females, as reflected in previous studies [12,13]. Finally, this study used only three subscales of the Conformity to Masculine Norms Inventory. While researchers support the use of selected masculine norms that are salient in a particular investigation [53,93], future studies should consider using the full spectrum of the scale to allow for a more comprehensive understanding of the role of masculinity in yoga participation, particularly among men.

\section{Conclusions}

This study examined the extent to which participation motives and conformity to certain masculine norms vary across gender and subgroups of yoga participant types. The findings point to the importance of differentiated messaging in yoga to capture a wider male audience. Although the top motives for yoga participation were consistent with previous studies, there were significant differences across gender, with male participants more likely to endorse taking up yoga as a supplementary activity and for competition and social recognition but less likely to cite coping and stress management, positive affect, mindbody integration, and health and fitness. When participant subgroups were considered, holistic motives were salient reasons even for male participants. The results of this study add to our understanding that not all male yoga participants are merely interested in yoga 
for its health and fitness benefits. Some male yoga participants do consider yoga more than just physical exercise and are interested in its psycho-spiritual teachings. These are important considerations when promoting yoga among men.

Supplementary Materials: The following are available online at https:/ / www.mdpi.com/article/ 10.3390/ijerph19020770/s1, Table S1: Structure coefficients for gender canonical function, Table S2: Correlations between age and participation motives (Overall), Table S3: Correlations between age and participation motives (Males), Table S4: Correlations between age and participation motives (Females), Table S5: Correlations between years of practice and participation motives (Overall), Table S6: Correlations between years of practice and participation motives (Males), Table S7: Correlations between years of practice and participation motives (Females), Table S8: Descriptive statistics of Conformity to Masculine Norms subscales by gender and participant subgroups, Table S9: Differences in participation motives across participant subgroups (Overall), Table S10: Differences in participation motives across participant subgroups (Males), and Table S11: Differences in participation motives across participant subgroups (Females).

Author Contributions: Conceptualization, J.Y.C., S.J.H.B. and I.V.; methodology, J.Y.C., S.J.H.B. and I.V.; formal analysis, J.Y.C.; investigation, J.Y.C., S.J.H.B. and I.V.; data curation, J.Y.C.; writingoriginal draft preparation, J.Y.C.; writing-review and editing, I.V.; supervision, I.V. and S.J.H.B.; project administration, J.Y.C.; funding acquisition, S.J.H.B. and J.Y.C. All authors have read and agreed to the published version of the manuscript.

Funding: This research was supported by the University of Southern Queensland's Physical Activity and Health PhD Scholarship, and the University of the Philippines Faculty Development Grant.

Institutional Review Board Statement: The study was conducted according to the guidelines of the Declaration of Helsinki and approved by the Human Research Ethics Committee of the UNIVERSITY OF SOUTHERN QUEENSLAND (H20REA109, approved on 8 May 2020).

Informed Consent Statement: Informed consent was obtained from all participants involved in the study.

Data Availability Statement: The data that support the findings of this study are available from the corresponding author, J.Y.C., upon reasonable request.

Acknowledgments: The authors would like to acknowledge the help of Svenja Wachsmuth and Peter Schneider in the translation of the Yoga Immersion Scale; Katrien De Cocker, Asuncion Sebastian, and Fiona Crawford-Williams in evaluating the additional participation motives items; and Realin Guiller in providing valuable feedback on the questionnaire.

Conflicts of Interest: The lead author is a yoga practitioner and teacher affiliated with some yoga studios in the Philippines and Australia. He declares these as potential conflicts of interest. The other authors declare no potential conflict of interest.

\section{References}

1. World Health Organization. WHO Traditional Medicine Strategy 2014-2023; World Health Organization: Geneva, Switzerland, 2013.

2. United Nations General Assembly. Resolution Adopted by the General Assembly on 11 December 2014. 69/131. International Day of Yoga; United Nations: New York, NY, USA, 2015.

3. So, W.W.Y.; Lu, E.Y.; Cheung, W.M.; Tsang, H.W.H. Comparing mindful and non-mindful exercises on alleviating anxiety symptoms: A systematic review and meta-analysis. Int. J. Environ. Res. Public Health 2020, 17, 8692. [CrossRef]

4. Cagas, J.Y.; Biddle, S.J.H.; Vergeer, I. When an activity is more than just exercise: A scoping review of facilitators and barriers for yoga participation. Int. Rev. Sport Exerc. Psychol. 2020. [CrossRef]

5. Lim, E.J.; Hyun, E.J. The impacts of pilates and yoga on health-promoting behaviors and subjective health status. Int. J. Environ. Res. Public Health 2021, 18, 3802. [CrossRef] [PubMed]

6. Vergeer, I.; Biddle, S.J.H. Mental health, yoga, and other holistic movement practices: A relationship worth investigating. Ment. Health Phys. Act. 2021, 21, 100427. [CrossRef]

7. Vergeer, I.; Johansson, M.; Cagas, J.Y. Holistic movement practices-An emerging category of physical activity for Exercise Psychology. Psychol. Sport Exerc. 2021, 53, 101870. [CrossRef]

8. Vergeer, I.; Klepac-Pogrmilovic, B. Diversification of physical activities: An exploration of provision characteristics of holistic movement practices in a large Australian city. Int. J. Environ. Res. Public Health 2021, 18, 10365. [CrossRef] [PubMed] 
9. Cramer, H. Yoga in Deustschland-Ergebnisse einer national repräsentativen umfrage (Yoga in Germany-Results of a Nationally Representative Survey). Forsch. Komplementärmedizin 2015, 22, 304-310. [CrossRef]

10. Wang, C.; Li, K.; Choudhury, A.; Gaylord, S. Trends in yoga, tai chi, and qigong use among US adults, 2002-2017. Am. J. Public Health 2019, 109, 755-761. [CrossRef]

11. Vergeer, I.; Bennie, J.A.; Charity, M.J.; Harvey, J.T.; van Uffelen, J.G.Z.; Biddle, S.J.H.; Eime, R.M. Participation trends in holistic movement practices: A 10-year comparison of yoga/Pilates and tai chi/qigong use among a national sample of 195,926 Australians. BMC Complementary Altern. Med. 2017, 17, 296. [CrossRef]

12. Vergeer, I.; Bennie, J.A.; Charity, M.J.; van Uffelen, J.G.Z.; Harvey, J.T.; Biddle, S.J.H.; Eime, R.M. Participant characteristics of users of holistic movement practices in Australia. Complementary Ther. Clin. Pract. 2018, 31, 181-187. [CrossRef]

13. Cramer, H.; Ward, L.; Steel, A.; Lauche, R.; Dobos, G.; Zhang, Y. Prevalence, patterns, and predictors of yoga use: Results of a U.S. nationally representative survey. Am. J. Prev. Med. 2016, 50, 230-235. [CrossRef]

14. Wang, F.; Szabo, A. Effects of yoga on stress among healthy adults: A systematic review. Altern. Ther. Health Med. 2020, 26, 58-64.

15. Chang, D.G.; Holt, J.A.; Sklar, M.; Groessl, E.J. Yoga as a treatment for chronic low back pain: A systematic review of the literature. J. Orthop. Rheumatol. 2016, 3, 1-8.

16. Cramer, H.; Lauche, R.; Haller, H.; Steckhan, N.; Michalsen, A.; Dobos, G. Effects of yoga on cardiovascular disease risk factors: A systematic review and meta-analysis. Int. J. Cardiol. 2014, 173, 170-183. [CrossRef]

17. Domingues, R.B. Modern postural yoga as a mental health promoting tool: A systematic review. Complementary Ther. Clin. Pract. 2018, 31, 248-255. [CrossRef] [PubMed]

18. Hendriks, T.; de Jong, J.; Cramer, H. The effects of yoga on positive mental health among healthy adults: A systematic review and meta-analysis. J. Altern. Complementary Med. 2017, 23, 505-517. [CrossRef] [PubMed]

19. Morris, T.; Roychowdhury, D. Physical activity for health and wellbeing: The role of motives for participation. Health Psychol. Rep. 2020, 8, 391-407. [CrossRef]

20. Molanorouzi, K.; Khoo, S.; Morris, T. Motives for adult participation in physical activity: Type of activity, age, and gender. BMC Public Health 2015, 15, 66. [CrossRef] [PubMed]

21. Sivaramakrishnan, D.; Fitzsimons, C.F.; Mutrie, N.; Baker, G. Perceptions of yoga among older adults: A qualitative approach. Ann. Yoga Phys. Ther. 2017, 2, 1035.

22. Spadola, C.E.; Rottapel, R.; Khandpur, N.; Kontos, E.; Bertisch, S.M.; Johnson, D.A.; Quante, M.; Khalsa, S.B.S.; Saper, R.B.; Redline, S. Enhancing yoga participation: A qualitative investigation of barriers and facilitators to yoga among predominantly racial/ethnic minority, low-income adults. Complementary Ther. Clin. Pract. 2017, 29, 97-104. [CrossRef]

23. Henrichsen-Schrembs, S.; Versteeg, P. A typology of yoga practitioners: Towards a model of involvement in alternative spirituality. Pract. Matters 2011, 4, 1-19.

24. Markland, D.; Ingledew, D.K. Exercise Participation Motives. In Intrinsic Motivation and Self-Determination in Exercise and Sport; Hagger, M.S., Chatzisarantis, N.L.D., Eds.; Human Kinetics: Champaign, IL, USA, 2007; pp. 23-34.

25. van Uffelen, J.G.Z.; Khan, A.; Burton, N.W. Gender differences in physical activity motivators and context preferences: A population-based study in people in their sixties. BMC Public Health 2017, 17, 624. [CrossRef]

26. Ley, C. Participation motives of sport and exercise maintainers: Influences of age and gender. Int. J. Environ. Res. Public Health 2020, 17, 7830. [CrossRef] [PubMed]

27. Grogan, S.; Conner, M.; Smithson, H. Sexuality, and exercise motivations: Are gay men and heterosexual women most likely to be motivated by concern about weight and appearance? Sex Roles 2006, 55, 567-572. [CrossRef]

28. Deaner, R.O.; Balish, S.M.; Lombardo, M.P. Sex differences in sports interest and motivation: An evolutionary perspective. Evol. Behav. Sci. 2016, 10, 73-97. [CrossRef]

29. Brems, C.; Justice, L.; Sulenes, K.; Girasa, L.; Ray, J.; Davis, M.; Freitas, J.; Shean, M.; Colgan, D. Improving access to yoga: Barriers to and motivators for practice among health professions students. Advances 2015, 29, 6-13. [PubMed]

30. Park, C.L.; Quinker, D.; Dobos, G.; Cramer, H. Motivations for adopting and maintaining a yoga practice: A national crosssectional survey. J. Altern. Complementary Med. 2019, 25, 1009-1014. [CrossRef]

31. Cagas, J.Y.; Biddle, S.J.H.; Vergeer, I. Yoga not a (physical) culture for men? Understanding the barriers for yoga participation among men. Complementary Ther. Clin. Pract. 2021, 42, 101262. [CrossRef] [PubMed]

32. Bottorff, J.L.; Seaton, C.L.; Johnson, S.T.; Caperchione, C.M.; Oliffe, J.L.; More, K.; Jaffer-Hirji, H.; Tillotson, S.M. An updated review of interventions that include promotion of physical activity for adult men. Sports Med. 2015, 45, 775-800. [CrossRef] [PubMed]

33. Hunt, K.; Wyke, S.; Gray, C.M.; Anderson, A.S.; Brady, A.; Bunn, C.; Donnan, P.T.; Fenwick, E.; Grieve, E.; Leishman, J.; et al. A gender-sensitised weight loss and healthy living programme for overweight and obese men delivered by Scottish Premier League football clubs (FFIT): A pragmatic randomised controlled trial. Lancet 2014, 383, 1211-1221. [CrossRef]

34. Henrichsen-Schrembs, S. Pathways to Yoga-Yoga Pathways: Modern Life Courses and the Search for Meaning in Germany. Ph.D. Thesis, Universität Bremen, Bremen, Germany, 2008.

35. Cartwright, T.; Mason, H.; Porter, A.; Pilkington, K. Yoga practice in the UK: A cross-sectional survey of motivation, health benefits and behaviours. BMJ Open 2020, 10, e031848. [CrossRef]

36. Mahalik, J.R.; Locke, B.D.; Ludlow, L.H.; Diemer, M.A.; Scott, R.P.J.; Gottfried, M.; Freitas, G. Development of the Conformity to Masculine Norms Inventory. Psychol. Men Masc. 2003, 4, 3-25. [CrossRef] 
37. Smiler, A.P. Thirty years after the discovery of gender: Psychological concepts and measures of masculinity. Sex Roles 2004, 50, 15-26. [CrossRef]

38. Griffith, D.M.; Gilbert, K.L.; Bruce, M.A.; Thorpe, R.J. Masculinity in men's health: Barrier or portal to healthcare? Mens Health Prim. Care Curr. Clin. Pract. 2016, 2, 19-31. [CrossRef]

39. Courtenay, W. Engendering health: A social constructionist examination of men's health beliefs and behaviors. Psychol. Men Masc. 2000, 1, 4-15. [CrossRef]

40. Sointu, E. Detraditionalisation, gender and alternative and complementary medicines. Sociol. Health Illn. 2011, 33, 356-371. [CrossRef]

41. Messner, M.A. Out of Play: Critical Essays on Gender and Sport; State University of New York Press: New York, NY, USA, 2007.

42. Baker, P. Men's health: A global problem requiring global solutions. Trends Urol. Mens Health 2016, 7, 11-14. [CrossRef]

43. Baker, P. Men's health: Time for a new approach. Phys. Ther. Rev. 2018, 23, 144-150. [CrossRef]

44. White, A.; de Sousa, B.; de Visser, R.; Hogston, R.; Madsen, S.A.; Makara, P.; Richardson, N.; Zatoński, W. The State of Men's Health in Europe: Extended Report; European Commission: Luxembourg, 2011.

45. Plummer, D. Sportophobia: Why do some men avoid sport? J. Sport Soc. Issues 2006, 30, 122-137. [CrossRef]

46. Ashton, L.M.; Hutchesson, M.J.; Rollo, M.E.; Morgan, P.J.; Collins, C.E. Motivators, and barriers to engaging in healthy eating and physical activity. Am. J. Mens Health 2017, 11, 330-343. [CrossRef]

47. Ashton, L.M.; Hutchesson, M.J.; Rollo, M.E.; Morgan, P.J.; Thompson, D.I.; Collins, C.E. Young adult males' motivators and perceived barriers towards eating healthily and being active: A qualitative study. Int. J. Behav. Nutr. Phys. Act. $2015,12,93$. [CrossRef]

48. Caperchione, C.M.; Vandelanotte, C.; Kolt, G.S.; Duncan, M.; Ellison, M.; George, E.; Mummery, W.K. What a man wants: Understanding the challenges and motivations to physical activity participation and healthy eating in middle-aged Australian men. Am. J. Mens Health 2012, 6, 453-461. [CrossRef]

49. Faul, F.; Erdfelder, E.; Lang, A.-G.; Buchner, A.G. Power 3: A flexible statistical power analysis program for the social, behavioral, and biomedical sciences. Behav. Res. Methods 2007, 39, 175-191. [CrossRef] [PubMed]

50. Markland, D.; Ingledew, D.K. The measurement of exercise motives: Factorial validity and invariance across gender of a revised Exercise Motivation Inventory. Br. J. Health Psychol. 1997, 2, 361-376. [CrossRef]

51. Cagas, J.Y.; Biddle, S.J.H.; Vergeer, I. Why Do People Do Yoga? Examining Motives Across Different Types of Yoga Participants. manuscript under review.

52. Parent, M.C.; Moradi, B. Confirmatory factor analysis of the Conformity to Masculine Norms Inventory and development of the Conformity to Masculine Norms Inventory-46. Psychol. Men Masc. 2009, 10, 175-189. [CrossRef]

53. Hammer, J.H.; Heath, P.J.; Vogel, D.L. Fate of the total score: Dimensionality of the Conformity to Masculine Norms Inventory-46 (CMNI-46). Psychol. Men Masc. 2018, 19, 645-651. [CrossRef]

54. Owen, J. Assessing the factor structures of the 55- and 22-item versions of the conformity to masculine norms inventory. Am. J. Mens Health 2011, 5, 118-128. [CrossRef] [PubMed]

55. Gaiswinkler, L.; Unterrainer, H.F.; Fink, A.; Kapfhammer, H.P. The relationship between yoga Immersion, psychological wellbeing, and psychiatric symptoms. Neuropsychiatrie 2015, 29, 29-35. [CrossRef] [PubMed]

56. Hair, J.F.J.; Black, W.C.; Babin, B.J.; Anderson, R.E. Multivariate Data Analysis, 7th ed.; Pearson Education: London, UK, 2013.

57. IBM Corp. IBM SPSS Statistics for Macintosh, Version 27.0; IBM Corp.: Armonk, NY, USA, 2020.

58. Tabachnick, B.G.; Fidell, L.S. Using Multivariate Statistics, 6th ed.; Pearson Education: London, UK, 2014.

59. Wertman, A.; Wister, A.V.; Mitchell, B.A. On and off the mat: Yoga experiences of middle-aged and older adults. Can. J. Aging La Rev. Can. Du Vieil. 2016, 35, 190-205. [CrossRef] [PubMed]

60. Frederick, C.; Ryan, R.M. Differences in motivation for sport and exercise and their relations with participation and mental health. J. Sport Behav. 1993, 16, 124-147.

61. Andreasson, J.; Johansson, T. The fitness revolution. Historical transformations in the global gym and fitness culture. Sport Sci. Rev. 2014, 23. [CrossRef]

62. Kidd, M.; Eatough, V. Yoga, well-being, and transcendence: An interpretative phenomenological analysis. Humanist. Psychol. 2017, 45, 258-280. [CrossRef]

63. Atkinson, M. Entering scapeland: Yoga, fell and post-sport physical cultures. Sport Soc. 2010, 13, 1249-1267. [CrossRef]

64. Feuerstein, G. The Yoga Tradition: Its History, Literature, Philosophy and Practice; Hohm Press: Prescott, AZ, USA, 2008.

65. Hasselle-Newcombe, S. Spirituality and mystical religion in contemporary society: A case study of British practitioners of the Iyengar method of yoga. J. Contemp. Relig. 2005, 20, 305-322. [CrossRef]

66. Sointu, E.; Woodhead, L. Spirituality, gender, and expressive selfhood. J. Sci. Study Relig. 2008, 47, 259-276. [CrossRef]

67. Courtenay, W.H. Constructions of masculinity and their influence on men's well-being: A theory of gender and health. Soc. Sci. Med. 2000, 50, 1385-1401. [CrossRef]

68. O'Neil, J.M. Gender role conflict research 30 years later: An evidence-based diagnostic schema to assess boys and men in counseling. J. Couns. Dev. 2013, 91, 490-498. [CrossRef]

69. Courtenay, W.H. Dying to be Men: Psychosocial, Environmental, and Biobehavioral Directions in Promoting the Health of Men and Boys; Routledge: London, UK, 2011.

70. Connell, R.W.; Messerschmidt, J.W. Hegemonic masculinity: Rethinking the concept. Gend. Soc. 2005, 19, 829-859. [CrossRef] 
71. Anderson, E.; McCormack, M. Inclusive Masculinity Theory: Overview, reflection, and refinement. J. Gend. Stud. 2016, 27, 547-561. [CrossRef]

72. Keshet, Y.; Simchai, D. The gender puzzle of alternative medicine and holistic spirituality: A literature review. Soc. Sci. Med. 2014, 113, 77-86. [CrossRef]

73. Brenton, J.; Elliott, S. Undoing gender? The case of complementary and alternative medicine. Sociol. Health Illn. 2014, 36, 91-107. [CrossRef] [PubMed]

74. Parent, M.C.; Smiler, A.P. Metric invariance of the Conformity to Masculine Norms Inventory-46 among women and men. Psychol. Men Masc. 2013, 14, 324-328. [CrossRef]

75. Mycek, M.K. Meatless meals and masculinity: How veg * men explain their plant-based diets. Food Foodways 2018, 26, 223-245. [CrossRef]

76. Verdonk, P.; Seesing, H.; de Rijk, A. Doing masculinity, not doing health? A qualitative study among Dutch male employees about health beliefs and workplace physical activity. BMC Public Health 2010, 10, 712. [CrossRef] [PubMed]

77. Levant, R.F.; Wimer, D.J. Masculinity constructs as protective buffers and risk factors for men's health. Am. J. Mens Health 2014, 8, 110-120. [CrossRef] [PubMed]

78. Liu, W.M.; Iwamoto, D.K. Conformity to masculine norms, Asian values, coping strategies, peer group influences and substance use among Asian American men. Psychol. Men Masc. 2007, 8, 25-39. [CrossRef]

79. Gard, T.; Noggle, J.J.; Park, C.L.; Vago, D.R.; Wilson, A. Potential self-regulatory mechanisms of yoga for psychological health. Front. Hum. Neurosci. 2014, 8, 770. [CrossRef]

80. Matud, M.P. Gender differences in stress and coping styles. Personal. Individ. Differ. 2004, 37, 1401-1415. [CrossRef]

81. Gattario, K.H.; Frisén, A.; Fuller-Tyszkiewicz, M.; Ricciardelli, L.A.; Diedrichs, P.C.; Yager, Z.; Franko, D.L.; Smolak, L. How is men's conformity to masculine norms related to their body image? Masculinity and muscularity across Western countries. Psychol. Men Masc. 2015, 16, 337-347. [CrossRef]

82. Hsu, K.; Iwamoto, D.K. Testing for measurement invariance in the Conformity to Masculine Norms- 46 across white and Asian American college men: Development and validity of the CMNI-29. Psychol. Men Masc. 2014, 15, 397-406. [CrossRef]

83. Dawson, N.; Hammer, J.H. No pain, no gains: Conformity to masculine norms, body dissatisfaction, and exercise dependence. Psychol. Men Masc. 2020, 21, 430-440. [CrossRef]

84. Evans, M.W., Jr.; Ndetan, H.; Ka Shekhon, V.; Williams, R.J.; Oliver, B.; Perko, M.; Woolsey, C.; Singh, K.P. Adult use of complementary and integrative approaches to improve athletic performance. Altern. Ther. Health Med. 2018, 24, 30-37. [PubMed]

85. Stussman, B.J.; Nahin, R.R.; Barnes, P.M.; Ward, B.W. U.S. physician recommendations to their patients about the use of complementary health approaches. J. Altern. Complementary Med. 2020, 26, 25-33. [CrossRef]

86. Clarke, T.C.; Barnes, P.M.; Black, L.I.; Stussman, B.J.; Nahin, R.L. Use of yoga, meditation, and chiropractors among U.S. adults aged 18 and over. NCHS Data Brief 2018, 325, 1-8.

87. Queensland Government. Queensland Sport, Exercise and Recreation Survey Adults 2018-Topline Results; Queensland Government: Brisbane, Australia, 2019.

88. Cramer, H.; Quinker, D.; Pilkington, K.; Mason, H.; Adams, J.; Dobos, G. Associations of yoga practice, health status, and health behavior among yoga practitioners in Germany-Results of a national cross-sectional survey. Complementary Ther. Clin. Pract. 2019, 42, 19-26. [CrossRef] [PubMed]

89. Cramer, H.; Sibbritt, D.; Park, C.L.; Adams, J.; Lauche, R. Is the practice of yoga or meditation associated with a healthy lifestyle? Results of a national cross-sectional survey of 28,695 Australian women. J. Psychosom. Res. 2017, 101, 104-109. [CrossRef] [PubMed]

90. Walls, H.L.; Peeters, A.; Loff, B.; Crammond, B.R. Why education and choice won't solve the obesity problem. Am. J. Public Health 2009, 99, 590-592. [CrossRef] [PubMed]

91. Antolihao, L.A. From baseball colony to basketball republic: Post-colonial transition and the making of a national sport in the Philippines. Sport Soc. 2012, 15, 1396-1412. [CrossRef]

92. Blanco, D.V. Sports governance stakeholders, actors, and policies in the Philippines: Current issues, challenges and future directions. Asia Pac. J. Sport Soc. Sci. 2016, 5, 165-186. [CrossRef]

93. Wong, Y.J.; Ho, M.R.; Wang, S.Y.; Miller, I.S. Meta-analyses of the relationship between conformity to masculine norms and mental health-related outcomes. J. Couns. Psychol. 2017, 64, 80-93. [CrossRef] [PubMed] 